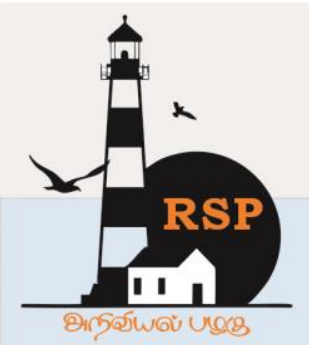

INTERNATIONAL RESEARCH JOURNAL ON

e-ISSN : $2582-4376$ ADVANCED SCIENCE HUB Open Access

RSP SCIENCE HUB

(The Hub of Research Ideas)

Available online at www.rspsciencehub.com

\title{
IoT Based Smart Irrigation for Multi Cropping System
}

Dr.T. Prakash ${ }^{1}$, Arun. $G^{2}$, Arun Kumar ${ }^{3}$.B, Deepan. $S^{4}$, Kalyana Venkata Ramanan ${ }^{5}$

${ }^{1}$ Professor, Department of Mechanical Engineering, SNS College of Technology, Coimbatore, Tamil

Nadu, India.

${ }^{2,3,4,5}$ UG Scholar, Department of Mechanical Engineering, SNS College of Technology, Coimbatore,

Tamil Nadu, India.

ttprakashmec@gmail.com ${ }^{1}$, arung.paraco98@gmail.com², arunbharathi2909@gmail.com³,

deepan.mech024@gmail.com ${ }^{4}$,ramanankvr15@gmail.com ${ }^{5}$

\begin{abstract}
An IoT based smart programmed multi cropping water system control gadget has been intended to encourage the automatic water supply of adequate water from a sump or well to field or multi cropping crops in all agricultural season. One of the main objective of this project is to avoid manpower for every irrigation purposes with proper interval based on multi cropping system. The technique utilized is to consistently monitor the real time gap and crop duration, fertilizer duration for feed to cropping system. And also how much water is required for each different kind of crops in multi cropping system. The pump motor will operate based on the microcontroller system output. The different valve system will operate by proper relay driver system for dripping the individual cropping system. The exclusive android application will help and monitor the real scenario for dripping system. The application is running based on the customer input data, once owner feed the data will stored in cloud and the microcontroller will get the data from cloud and control the valve systems. The manual setting system also included in this gadget. The arduino board is specially designed circuit board for programming and prototyping with ATMEL microcontroller. The microcontroller used in this arduino is ATmega 328 which is in-built in arduino board and the coding are done in embedded $C$.
\end{abstract}

Keywords: Internet of Things, Multi cropping, Node MCU, Microcontroller, RTC

\section{Introduction}

Irrigation and fertiliser feeding are the two most important factors, which decide the agriculture productivity and its production. As India consumes $80 \%$ of total available water resources for irrigation purpose, there is an urgent need to reduce water consumption using advanced scientific techniques. The water is the biggest resource for the development of life on earth. Now days, it is scarce. In this way, we have to utilize it with absolute consideration. During water system water wastage ought to be stayed away from. The plants or harvest ought to be flooded just when they should be. At the point when plants come to pass more measure of water, the relative humidity of atmosphere increases. The presence of large amount of relative humidity increases the chances of disease attack. So, the status of soil moisture in the field requires periodic inspection, from where one can come to know, when the next irrigation should be done and how much amount of water should be applied. IoT based wireless sensor networks have a lot of applications in agriculture, such as monitoring atmospheric temperature and humidity, soil moisture content etc. The main units of sensor network are data acquisition or sensor unit, processing unit, communication protocol and power supply unit. 


\section{Literature Review}

In this proposed IoT based Multi cropping system Figure 1 shows contains powerful exclusive microcontroller, Real time clock in order to track real time for system on/off. In this system have an option of manual mode and automatic mode. User or land owner can choose their operation based on their choice.

\section{a. Block Diagram}

Manual mode contains four sensitive soft switches namely mode, crop 1 timer, crop 2 timer and crop 3 timer. The $4 * 20$ Liquid crystal Display shows the operation and act as a user interface system. The relay driver system contains $1 \mathrm{k}$ resistor and Microcontroller will deliver only $5 \mathrm{~V}$ amplitude pulse. That pulse will not drive the external relay that why we are using relay driver circuit. In this proposed system interconnected with Real time Clock (RTC), because it will track real time, hour, month and year. $12 \mathrm{~V}$ powerful high sensitive solenoid relay used to turn on or off the valve system for dripping. The entire power supply taking from $230 \mathrm{~V}, 50 \mathrm{~Hz}$ AC supply to DC converter, otherwise battery will supply. Solar power supply also used for system run. Figure 2 shows the proposed irrigation system for Multi cropping system. Three main valves are used for individual cropping systems. Each valve supplies water system for each crops. The main valve supply to their individual branch water piping system. The fertilizer valve system also supply heart valve system. Based on the selection crop by customer, fertilizer mixer $\mathrm{N}, \mathrm{P}, \mathrm{K}$ will feed to crops.

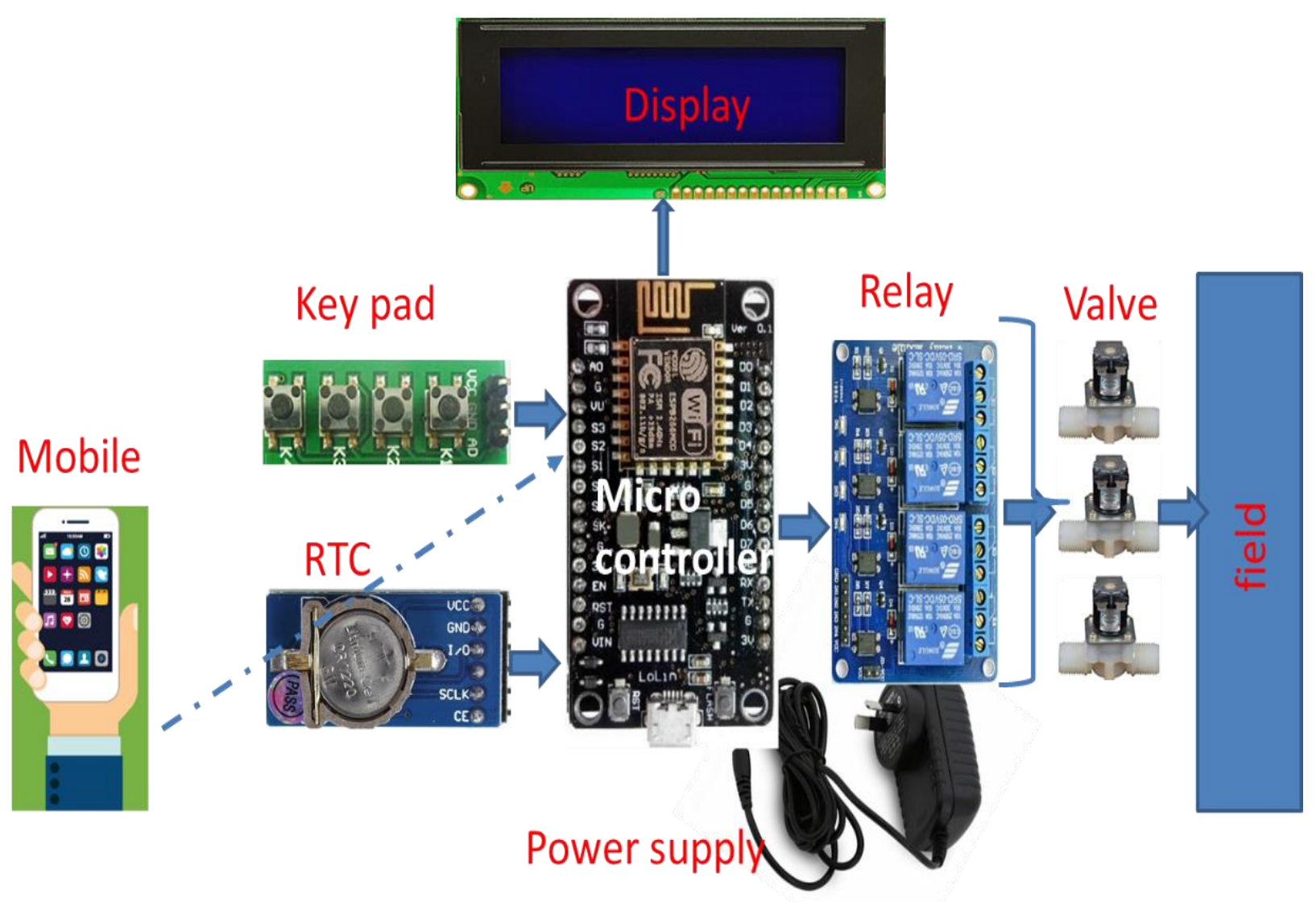

Figure 1. Block Diagram of Proposed System 


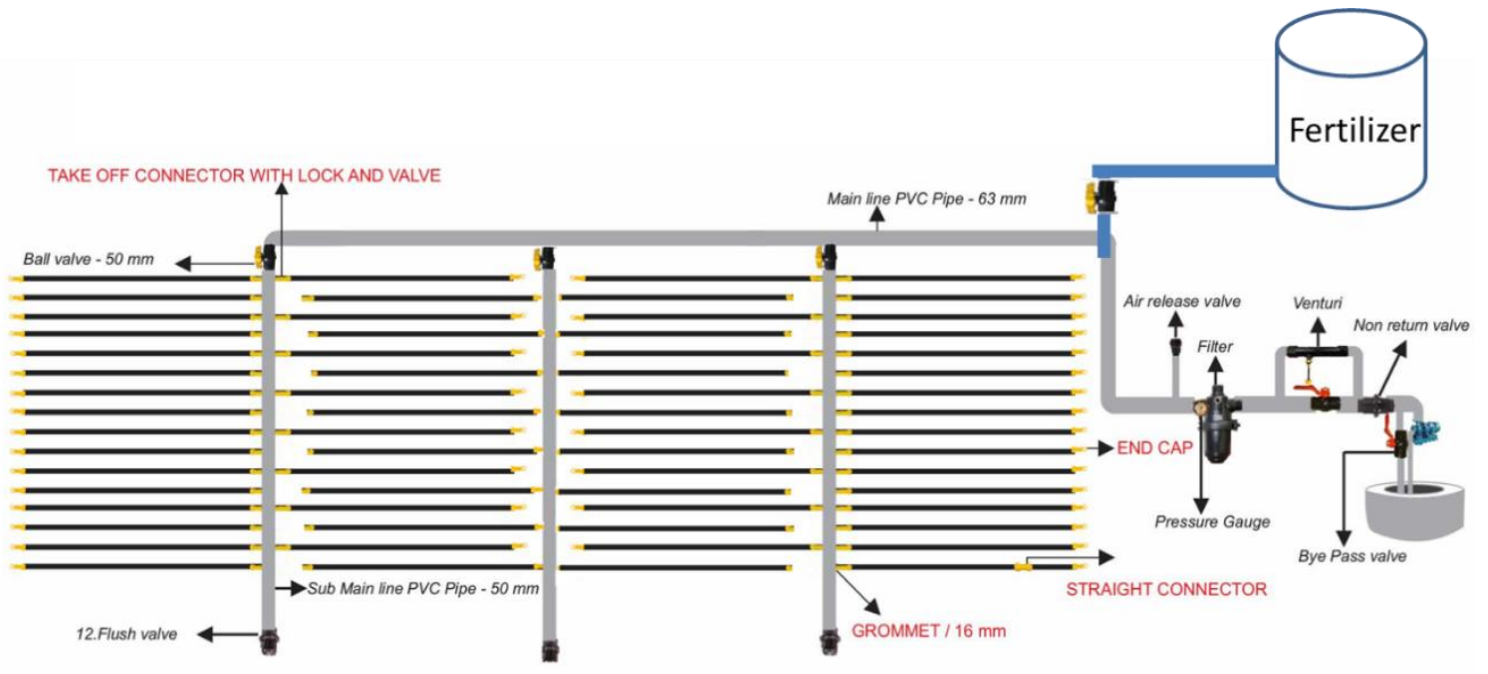

Figure 2. Proposed irrigation system for Multi cropping

2N2222 transistor, it will turn on/off the external relay system. Microcontroller will deliver only 5V amplitude pulse.[1-5] That pulse will not drive the external relay that why we are using relay driver circuit. In this proposed system interconnected with Real time Clock (RTC), because it will track real time, hour, month and year. $12 \mathrm{~V}$ powerful high sensitive solenoid relay used to turn on or off the valve system for dripping. The entire power supply taking from $230 \mathrm{~V}, 50 \mathrm{~Hz}$ AC supply to DC

\section{MIT APP Inventor}

MIT App Inventor is a web platform designed to show computational thinking concepts through development of mobile applications. Every people can create applications by dragging and

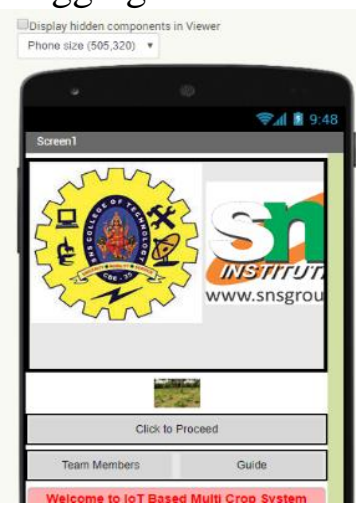

Figure 3. MIT App Inventor Blocks

The design editor, or designer Fig. 3., is drag and drop interface to lay out the elements of the application's user interface (UI). The blocks editor Fig. 4 is a domain during which application creators can outwardly spread out the rationale of converter, otherwise battery will supply. Solar power supply also used for system run. Figure 2 shows the proposed irrigation system for Multi cropping system. Three main valves are used for individual cropping systems. Each valve supplies water system for each crops. The main valve supply to their individual branch water piping system. The fertilizer valve system also supply heart valve system. Based on the selection crop by customer, fertilizer mixer $\mathrm{N}, \mathrm{P}, \mathrm{K}$ will feed to crops.

dropping components into a design view and using a visual blocks language to program application behaviour. The MIT App Inventor interface includes two main editors: the planning editor and therefore the blocks editor.

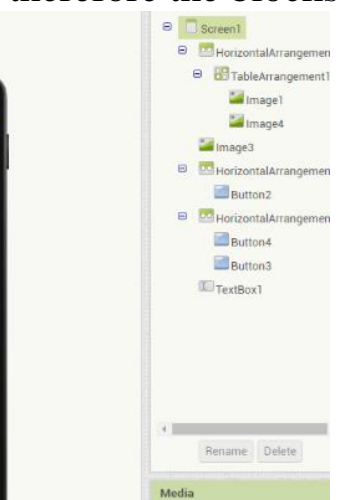

their applications utilizing shading coded hinders that snap together like unique pieces to clarify the program. To aid in development and testing, App Inventor provides a mobile app called the App Inventor Companion (or just "the Companion") 
that developers can use to check and adjust the behaviour of their apps in real time. Right now, can rapidly assemble a portable application and promptly start to emphasize and test.

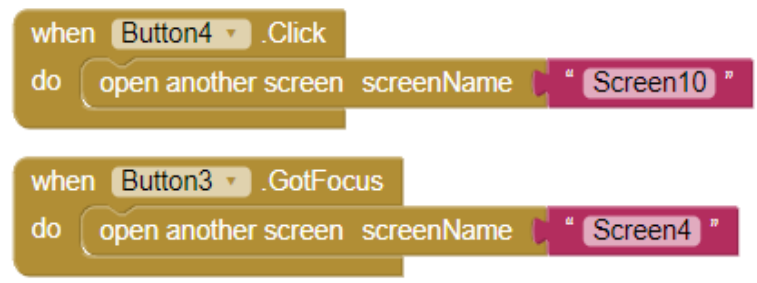

when Button2 - Click

do Open another screen screenName "Screen2"

\section{Figure 4. MIT App Inventor Designer}

The smartphone is an information nexus in today's digital age, with access to an almost infinite supply of content on the online , including rich sensors and private data. Be that as it may, individuals experience issues bridling the full intensity of these universal gadgets for themselves and their networks. Most smartphone users consume technology without having the ability to supply it, albeit local problems can often be solved with mobile devices. MIT App Inventor is intended to democratize this innovation and is utilized as a device for learning computational speculation during a kind of instructive settings, educating individuals to create apps to solve problems in their communities. MIT App Inventor is a web development platform that anyone can leverage to unravel real-world problems. It gives an online "What you see is what you get" (WYSIWYG) editor for building PDA applications concentrating on the Android and iOS working systems. It utilizes a square put together programing language worked with respect to Google Blockly (Fraser, 2013) and roused by dialects like StarLogo TNG (Begel and Klopfer, 2007) and Scratch (Resnick et al., 2009; Maloney, Resnick, Rusk, Silverman, and Eastmond, 2010), enabling anybody to fabricate a cell phone application to address an issue. Until this point in time, 6.8 million individuals in more than 190 nations have utilized App Inventor to make more than 24 million applications. We offer the interface in excess of twelve dialects. People round the world use App Inventor to supply mobile solutions to real problems in their families, communities, and therefore the world. $[6-10]$ The stage has likewise been adjusted to serve prerequisites of increasingly explicit populaces, such as building applications for crisis/specialists on call (Jain et al., 2015) and mechanical autonomy (Papadakis and Orfanakis, 2016). Right now, depict the objectives of MIT App Inventor and the manner in which they need impacted our plan and improvement from the program's origin at Google in 2008, through the movement to MIT, right up 'til the present time. We talk about the educational estimation of MIT App Inventor and its utilization as an instrument to appear and support individuals of any age to think and act computationally. We also describe three applications developed by students in several parts of the planet to unravel real issues in their communities. We conclude by discussing the restrictions and benefits of tools like App Inventor and proposing new directions for research. [11-14]

\section{Design using the companion}

A key feature of MIT App Inventor is its live development environment for mobile applications. Application Inventor gives this by methods for a buddy application introduced on the client's cell phone. The App Inventor web interface sends code to the buddy 
application, which deciphers the code and shows the application continuously to the designer (Fig. 5). This way, the user can change the app's interface and behaviour in real time. for instance, a student making a game involving the ball component might want to bounce the ball off the sting of the play area. However, an initial implementation may need the ball hit the wall then stop. After discovering the Ball. Edge Reached occasion, the researcher can include the occasion and update the heading of the ball utilizing the Ball Bounce technique.
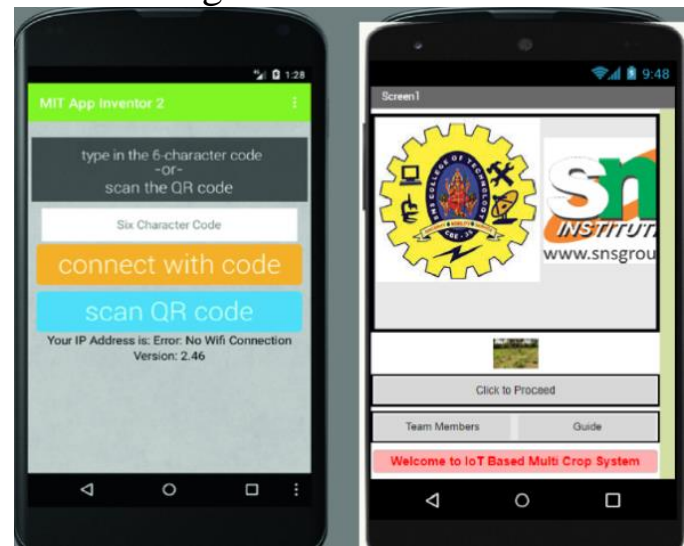

Figure 5. The MIT Companion app interface for Android (left). After establishing a connection with the user's browser session, the active project is displayed in the companion app (right)

\section{Hardware}

NODEMCU (esp8266) has been selected because the controller for this technique thanks to its compact size, compatibility, easy interfacing over several other sort of controller including Programmable microcircuit (PIC), Programmable Logic Controller (PLC) et al. . ESP8266 is an open source firmware that's built on top of the chip manufacturer's proprietary SDK.

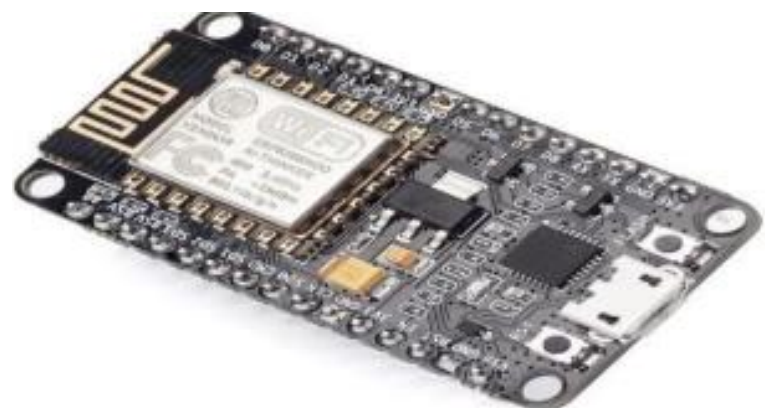

Figure.6. Diagram of NodeMCU (esp8266)

The firmware provides an easy programming environment, which may be a very simple and fast scripting language The ESP8266 chip incorporates on a typical circuit card . The board features a built-in USB port that's already wired up with the chip, a hardware push button , Wi-Fi antenna, LED lights, and standard-sized GPIO (General Purpose Input Output) pins which will plug into a bread board. Figure-6 shows the diagram of NODEMCU (ESP8266).It has Processor called L106 32bit RISC microprocessor core supported the Tensilica Xtensa Diamond Standard 106Micro running at $80 \mathrm{MHz}$ and features a memory of $32 \mathrm{Kbit}$ guidance RAM ,32 Kbit guidance store RAM, 80 Kbit client information RAM\&16 Kbit ETS framework information RAM. it's inbuilt Wi-Fi module of IEEE $802.11 \mathrm{~b} / \mathrm{g} / \mathrm{n}$ Wi-Fi.

\section{Result and Conclusion}

As a whole, the project are often rated as successful having the ability to satisfy the first 
target alright and obtain the device working for the exhibition. During the work, trying the new things and getting failed numerous times taught quite good lessons which can be treasured for business life. Many new things were learnt during the project, microcontroller programming being the another notable. The proposed IoT based smart irrigation system for multi cropping system was tested in simulation field also as prototype. The prototype gave good result with proper operation. during this way we will eliminate man power for irrigation system also as proper fertiliser feeding system. The android app or MIT app comminute with cloud and operate microcontroller. The relays are properly did their works and operate the valves.

In real time web based multi cropping drip automation system this project are often extended in future to make sure the high security, the fertiliser level and dripping water quantity are often monitored through online proper flow sensors. In future we will develop exclusive application with domain based system. during this system we will implement multiple units for various fields.

\section{References}

[1] D. Norris, Smart Home Automation Based on IOT and Android Technology M.Abivandhana1, K.Divya2, D.Gayathri3, R.RuhinKouser4 Student1, 2, 3, Assistant Professor4 Department of CSE Kingston Engineering College, Katpadi, Vellore, India

[2] International Journal of Innovative Studies in Sciences and Engineering Technology (IJISSET) IoT Based Home Automation Using Raspberry PI ISSN 2455-4863 (Online) www.ijisset.org Volume: 3 Issue: 4 | April 2017

[3] Mark Murphy (2011): Beginning Android 3, Après. ISBN-13 (pbk): 978-1-4302-3297-1 ISBN-13 (electronic): 978-1-4302- 3298-8

[4] Addison-Wesley (2011): Android Wireless Application Development, 2nd edition ISBN-13: 978-0-321-74301-5 ISBN10: 0321-74301-6

[5] Wikipedia (2009). Home Automation. From http://en. Wikipedia. org/wiki/Home_ automation. Retrievedon 20/5/2018
[6] Martin Bates(2006). Interfacing PIC Microcontrollers Embedded Design by Interactive Simulation. Newnes, London.

[7] S. Alam, M. M. R. Chowdhury, and J. Noll, "Senaas: An event-driven sensor virtualization approach for internet of things cloud," in Networked Embedded Systems for Enterprise Applications (NESEA), 2010 IEEE International Conference on, November 2010.

[8] Z. Schelby, K. Hartke, and C. Bormann, (Aug. 28, 2013) „,"Constrained application protocol (CoAP), ${ }^{\text {cee }}$ CoRE Working Group Internet-Draft. [Online].

[9] Ciubotaru-Petrescu, B., Chiciudean, D., Cioarga, R., \& Stanescu, D. Wireless Solutions for Telemetry in Civil Equipment and Infrastructure Monitoring.

[10] K.. Venkatesan and Dr. U. Ramachandraiah, Networked Switching and Polymorphing Control of Electrical Loads with Web and Wireless Sensor Network, 2015 International Conference on Robotics, Automation, Control and Embedded Systems (RACE), Chennai, (2015), 1-9.

[11] Shopan Dey, Ayon Roy and Sandip Das, Home automation using IOT, IRJET, 2(3) (2016), 1965-1970.

[12] Vishwateja Mudiam Reddy, Naresh Vinay, Tapan Pokharna and Shashank Shiva Kumar Jha, Internet of Things Enabled Smart Switch, Thirteenth International Conference on Wireless and Optical Communications Networks (WOCN), Hyderabad, (2016), 1-4.

[13] Warsuzarina Mat Jubadi and Normaziah Zulkifli, Programmable Infrared Accessory Light Switch, International Conference on Intelligent and Advanced Systems, Kuala Lumpur,(2007), 1130-1134.

[14] Shih-Pang Tseng, Bo Rong Li, Jun-Long Pan, and Chia Ju Lin, An Application of Internet of Things with Motion Sensing on Smart House, International Conference on Orange Technologies, Xian, (2014), 65-68. 